\title{
Effect of the electrodeposition potential on the magnetic properties of FeCoNi films
}

\author{
Setia Budi ${ }^{1 * *}$, Sukro Muhab $^{1}$, Agung Purwanto $^{1}$, Budhy Kurniawan $^{2}$, Azwar ManaF $^{2, \dagger}$ \\ ${ }^{1}$ Department of Chemistry, Faculty of Mathematics and Sciences, Universitas Negeri Jakarta, Jl. Rawamangun Muka, \\ Jakarta 13220, Indonesia \\ ${ }^{2}$ Department of Physics, Faculty of Mathematics and Natural Sciences, Universitas Indonesia, Depok 16424, Indonesia
}

The effect of electrodeposition potential on the magnetic properties of the FeCoNi films has been reported in this paper. The FeCoNi electrodeposition was carried out from sulfate solution using potentiostatic technique. The obtained FeCoNi films were characterized by X-ray diffractometer (XRD), atomic absorption spectrometer (AAS) and vibrating sample magnetometer (VSM). It has been shown that the electrodeposition potential applied during the synthesis process determines the magnetic characteristics of FeCoNi films. The more negative potential is applied, the higher Ni content is in the FeCoNi alloy. At the same time, Co and Fe showed almost similar trend in which the content decreased with an increase in applied potential. The mean crystallite size of FeCoNi films was ranging from $11 \mathrm{~nm}$ to $15 \mathrm{~nm}$. VSM evaluation indicated that the FeCoNi film is a ferromagnetic alloy with magnetic anisotropy. The high saturation magnetization of FeCoNi film was ranging from $86 \mathrm{~A} \cdot \mathrm{m}^{2} / \mathrm{kg}$ to $105 \mathrm{~A} \cdot \mathrm{m}^{2} / \mathrm{kg}$. The film is a soft magnetic material which was revealed by a very low coercivity value in the range of $1.3 \mathrm{kA} / \mathrm{m}$ to $3.7 \mathrm{kA} / \mathrm{m}$. Both the saturation magnetization and coercivity values decreased at a more negative electrodeposition potential.

Keywords: magnetic properties; flexible substrate; soft magnetic film; electrodeposition potential; FeCoNi film

\section{Introduction}

FeCoNi has been recognized as a Fe-group alloy that possesses excellent magnetic properties coupled with remarkable thermal stability. Since the last few decades, researchers have paid their attention to investigate the magnetic properties of FeCoNi for data storage applications and magnetic read/write heads [1]. The reason was the fact that magnetic data storage media are urgently required for the applications in many electronic devices, such as computers, portable music devices, vehicle navigation systems, and many others [2]. The synthesis of FeCoNi alloys with improved magnetic properties becomes more challenging to fulfil the increasing requirements of high storage capacity and fast information transfer rate devices. The magnetic storage devices with higher storage density require materials with a high

\footnotetext{
*E-mail: setiabudi@unj.ac.id

†E-mail: azwar@ui.ac.id
}

saturation magnetization value and a very low coercivity $[3,4]$.

Transition metals, like $\mathrm{Fe}$, $\mathrm{Co}$ and $\mathrm{Ni}$, are ferromagnetic materials which are largely used for magnetic alloys production. Their magnetic properties are characterized by low coercivity [5] and high saturation magnetization $[6,7]$. Over many years, the researchers have used FeCoNi alloys for soft magnet applications using the conventional method, such as mechanical alloying $[3,6,8]$. However, this technique may produce inappropriate FeCoNi powder, while for magnetic media storage applications, which require soft magnetic material, the most suitable is the film form. Several familiar methods to synthesize metal or alloy in the form of deposit or a film are known, such as electrodeposition technique [9-12], solgel [13], and magnetron sputtering [14]. Among them, electrodeposition employed for the synthesis of the magnetic films is more cost-effective compared with other preparation techniques. In the electrodeposition process, the applied current 
and potential are essential variables that should be adjusted to control kinetics of the deposition process. By altering the electrodeposition potential, microstructure and chemical composition of the transition metals alloys, such as $\mathrm{CoNiCu}$ [15] and CoNi [16], can be modified. This condition leads to significant changes in their magnetic properties $[10,16]$. Since the magnetic properties of the FeCoNi also depend on its microstructure and composition, it is interesting to investigate the role of these electrodeposition variables on the electrodeposited FeCoNi films.

In our previous works $[15,16]$, the FeCoNi film was successfully electrodeposited on a flexible substrate of polyethylene terephthalate coated with indium tin oxide (ITO-PET). The using of a flexible substrate was motivated by the recent demand for flexible magnetic films due to the development of flexible electronic devices [17, 18]. Herein, we investigated the influence of electrodeposition potential on magnetic properties of the FeCoNi film electrodeposited on the ITO-PET substrate. The FeCoNi deposits obtained in this work demonstrated properties of typical soft magnetic alloys with low coercivity and high saturation which could be controlled through the applied electrodeposition potential. The relation between the applied potential, chemical composition and magnetic properties of the film was discussed.

\section{Materials and method}

The electrodeposition of $\mathrm{FeCoNi}$ was performed in sulfate electrolyte system, which was freshly prepared from analytical grade $\mathrm{FeSO}_{4} \cdot 7 \mathrm{H}_{2} \mathrm{O}, \quad \mathrm{CoSO}_{4} \cdot 7 \mathrm{H}_{2} \mathrm{O}, \quad \mathrm{NiSO}_{4} \cdot 6 \mathrm{H}_{2} \mathrm{O}$, $\mathrm{H}_{3} \mathrm{BO}_{3}$ precursors and the food grade $\mathrm{C}_{7} \mathrm{H}_{4} \mathrm{NNaO}_{3} \mathrm{~S} \cdot 2 \mathrm{H}_{2} \mathrm{O}$ chemical. The concentration of the electrolytes used in the electrodeposition process for the FeCoNi preparation is listed in Table 1. The electrodeposition was carried out under various electrodeposition potentials using EDAQ potentiostat of EA163 type in the potentiostatic mode. The substrate used in this work was polyethylene terephthalate coated with indium tin oxide (ITO-PET) with a sheet resistance of $10 \Omega /$ sq supplied by Kintec. The coated ITO is amorphous
Table 1. Concentration of the solution used as metal sources in the electrodeposition process.

\begin{tabular}{lc}
\hline Chemicals & Molarities [mol/L] \\
\hline \hline $\mathrm{FeSO}_{4} \cdot 7 \mathrm{H}_{2} \mathrm{O}$ & 0.010 \\
$\mathrm{CoSO}_{4} \cdot 7 \mathrm{H}_{2} \mathrm{O}$ & 0.020 \\
$\mathrm{NiSO}_{4} \cdot 6 \mathrm{H}_{2} \mathrm{O}$ & 0.170 \\
$\mathrm{H}_{3} \mathrm{BO}_{3}$ & 0.400 \\
$\mathrm{C}_{7} \mathrm{H}_{4} \mathrm{NNaO}_{3} \mathrm{~S} \cdot 2 \mathrm{H}_{2} \mathrm{O}$ & 0.008 \\
\hline
\end{tabular}

phase composed of $\mathrm{In}_{2} \mathrm{O}_{3}: \mathrm{SnO}_{2}$ at a ratio of 9:1 with a thickness of $\sim 180 \mathrm{~nm}$. A platinum wire and $\mathrm{Ag} / \mathrm{AgCl}$ acted as a counter and a reference electrode, respectively. The electrodeposition potential applied in the process was varied from $-1.00 \mathrm{~V}$ to $-2.00 \mathrm{~V}$ relative to $\mathrm{Ag} / \mathrm{AgCl}$ electrode with the deposition time of 5 minutes. In this case, the electrodeposition processes were carried at potentials higher than the standard reduction potential of $\mathrm{Fe}^{2+}(-0.44 \mathrm{~V}), \mathrm{Co}^{2+}(-0.28 \mathrm{~V})$, and $\mathrm{Ni}^{2+}(-0.25 \mathrm{~V})$ due to the co-deposition overpotential of the metal ions [19, 20].

The mean crystallite size of FeCoNi films was evaluated by Panalytical EMPYREAN X-ray diffractometer (XRD) employing $\mathrm{CuK} \alpha$ radiation $(\lambda=1.541874 \AA)$. The obtained XRD patterns were compared to the standard pattern of $\mathrm{FeCoNi}$ alloy from Crystallography Open Database (COD) number 96-900-00900 [21]. The mean crystallite size of the FeCoNi films was then determined by Rietveld refinement method using HighScore Plus software. The mass content of $\mathrm{Fe}, \mathrm{Co}$ and $\mathrm{Ni}$ in the deposits was quantitatively determined using a Shimadzu AA7000 atomic absorption spectrometer (AAS). Magnetic properties were measured for $4 \mathrm{~mm} \times 4 \mathrm{~mm}$ FeCoNi films using LakeSore 7404 vibrating sample magnetometer (VSM) equipped with a magnetic field (H) up to $900 \mathrm{kA} / \mathrm{m}$.

\section{Results and discussion}

$\mathrm{X}$-ray diffraction patterns of the $\mathrm{FeCoNi}$ alloy films deposited at various negative potentials are compared in Fig. 1. Obviously, all patterns show a diffraction peak at a diffraction angle $2 \theta$ of $44.17^{\circ}$ related to $\left(\begin{array}{lll}1 & 1 & 1\end{array}\right)$ plane 
of FeCoNi. The sample prepared at a low potential $(-1.00 \mathrm{~V}$ vs. $\mathrm{Ag} / \mathrm{AgCl})$ shows additional peaks corresponding to the diffraction peaks of ITO and PET substrates [22]. Since all of the FeCoNi films were electrodeposited in the same deposition time, the pattern was then attributed to very thin deposit due to the low deposition rate of $\mathrm{Fe}, \mathrm{Co}$ and $\mathrm{Ni}$ at $-1.00 \mathrm{~V}$ vs. $\mathrm{Ag} / \mathrm{AgCl}$ and hence, it allowed the $\mathrm{X}$ ray to reach the substrate. Nevertheless, these additional peaks vanished in the films obtained at more negative values of the electrodeposition potential $(-1.10 \mathrm{~V}$ to $-2.00 \mathrm{~V}$ vs. $\mathrm{Ag} / \mathrm{AgCl})$. It is also noted that another diffraction peak appears at another diffraction angle $51.57^{\circ}$, which corresponds to the $\left(\begin{array}{lll}2 & 0 & 0\end{array}\right)$ plane of FeCoNi [21]. This peak was observed in all samples prepared through electrodeposition at potential ranging from $-1.50 \mathrm{~V}$ to $-2.00 \mathrm{~V}$ vs. $\mathrm{Ag} / \mathrm{AgCl}$. All diffraction patterns shown in Fig. 1 have been matched with the results on the phase structure evaluation of mechanically alloyed FeCoNi reported by Pikula [3]. The formation of FCC solid solution of FeCoNi alloy in the film samples obtained in the current work was then confirmed. Additionally, the patterns shown in Fig. 1 are characterized by broadened peaks reflecting the existence of ultrafine crystallites in the films. The mean crystallite size was found in a small range between $11 \mathrm{~nm}$ and $15 \mathrm{~nm}$. Hence, there is no substantial influence of electrodeposition potential on the mean crystallite size of the FeCoNi films. However, when the mean crystallite size of FeCoNi films is compared with that obtained by mechanical alloying technique [3], it is realized that the mean crystallite size of the current alloy films is much finer than that of mechanically alloyed FeCoNi.

The atomic fraction (at.\%) of $\mathrm{Fe}, \mathrm{Co}$ and $\mathrm{Ni}$ contained in the FeCoNi alloy films deposited at different electrodeposition potentials is plotted in Fig. 2a. The plot indicates that the electrodeposition potentials applied during the film deposition control the atomic fraction of $\mathrm{Fe}, \mathrm{Co}$ and $\mathrm{Ni}$ atoms. The more negative potential is applied, the more abundant concentration of $\mathrm{Ni}$ is in the film. In addition, it can be seen that $\mathrm{Fe}$ and Co concentration were found to decrease at more negative potentials. In this case, Fe content decreased from 22.68 at. $\%$

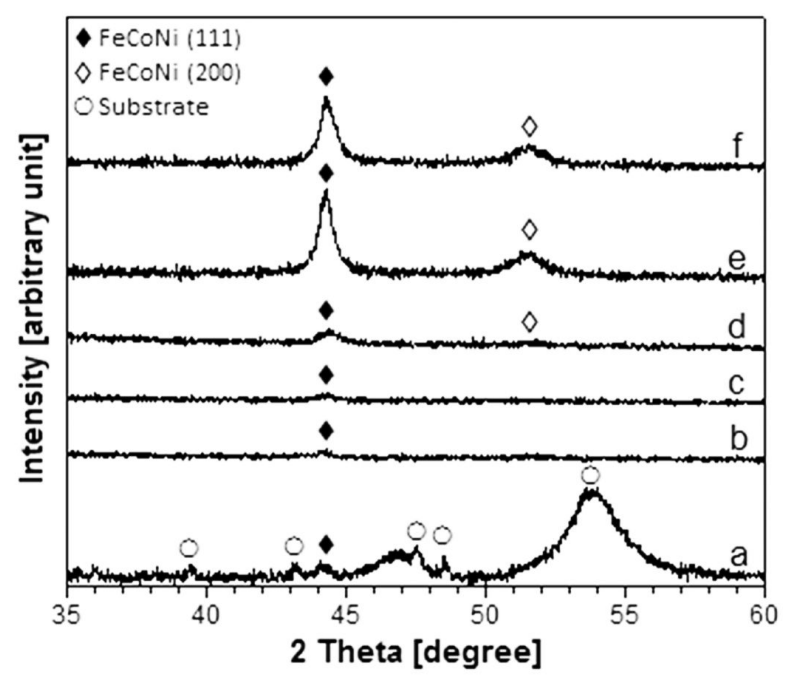

Fig. 1. X-ray diffraction patterns of the FeCoNi films deposited at electrodeposition potentials of (a) $-1.00 \mathrm{~V}$, (b) $-1.10 \mathrm{~V},(\mathrm{c})-1.30 \mathrm{~V}$, (d) $-1.50 \mathrm{~V}$, (e) $-1.75 \mathrm{~V}$ and (f) $-2.00 \mathrm{~V}$ vs. $\mathrm{Ag} / \mathrm{AgCl}$.

at a potential of $-1.10 \mathrm{~V}$ vs. $\mathrm{Ag} / \mathrm{AgCl}$ to 10.18 at.\% at a potential of $-2.00 \mathrm{~V}$ vs. $\mathrm{Ag} / \mathrm{AgCl}$. Similarly, the Co content decreased from 40.77 at. $\%$ to 20.70 at.\%. Consequently, the alloy was enriched with $\mathrm{Ni}$ as the applied potential was getting more negative. Fig. $2 b$ shows the plots of $\mathrm{Ni} / \mathrm{Fe}$ and $\mathrm{Ni} / \mathrm{Co}$ atomic ratios versus the applied potential. As the potential increases negatively from $-1.00 \mathrm{~V}$ to $-1.75 \mathrm{~V}$ vs. $\mathrm{Ag} / \mathrm{AgCl}$, the $\mathrm{Ni} / \mathrm{Fe}$ and $\mathrm{Ni} / \mathrm{Co}$ ratios increase almost linearly. Nevertheless, at a potential lower than $-1.75 \mathrm{~V}$ vs. $\mathrm{Ag} / \mathrm{AgCl}$, no further increase is noticed. The difference between the ratio values of $\mathrm{Ni} / \mathrm{Fe}$ and $\mathrm{Ni} / \mathrm{Co}$ must be related to the standard potential of $\mathrm{Ni}^{2+}$.

The relatively high content of $\mathrm{Co}$ and $\mathrm{Fe}$ in the film obtained from electrolyte with high $\mathrm{Ni}^{2+}$ ions concentration, especially observed at $-1.00 \mathrm{~V}$ vs. $\mathrm{Ag} / \mathrm{AgCl}$, indicates anomalous co-deposition in the electrodeposition process. Anomalous codeposition is a phenomenon showing a high deposition preference of less noble metal, namely $\mathrm{Fe}$ and $\mathrm{Co}$, compared to more noble metal $\mathrm{Ni}$. However, at more negative potential $(\leqslant-1.10 \mathrm{~V}$ vs. $\mathrm{Ag} / \mathrm{AgCl})$ the $\mathrm{Ni}$ content was found to increase gradually when the electrodeposition potential shifted to more negative ones. It can 
be assumed that the anomalous co-deposition characteristics decreased at more negative potential. This results could be attributed to the high overpotential of $\mathrm{Ni}[19,23]$ which leads to rising the deposition rate of $\mathrm{Ni}$ at more negative potential. It was also found that the change of Co content at different electrodeposition potentials is similar to that of Fe (Fig. 2a). In fact, the standard reduction potential of $\mathrm{Co}$ is closer to that of $\mathrm{Ni}$ rather than $\mathrm{Fe}$. This case can be related to the composition ratio value (CRV) of Co that exhibits similar behavior to that of $\mathrm{Fe}$ [24].

It was recorded in our previous report that although the standard reduction potential of $\mathrm{Ni}^{2+}$ is lower than that of both $\mathrm{Fe}^{2+}$ and $\mathrm{Co}^{2+}$, the $\mathrm{Ni}^{+2}$ ion possesses the highest overpotential among the all investigated metal ions [14]. The high overpotential of $\mathrm{Ni}^{+2}$ has led to a higher deposition rate of $\mathrm{Ni}$ at a high electrodeposition potential difference compared with those of $\mathrm{Fe}$ and $\mathrm{Co}$. Consequently, the atomic fraction of $\mathrm{Ni}$ in the film is much higher than that of $\mathrm{Fe}$ and $\mathrm{Co}$. In Fig. 2b, the atomic ratio between $\mathrm{Co}$ and $\mathrm{Fe}$ was also plotted. There is almost no change in the atomic ratio between $\mathrm{Co}$ and $\mathrm{Fe}$ atoms with the applied potential in the range of $-1.1 \mathrm{~V}$ to $-2.00 \mathrm{~V}$ vs. $\mathrm{Ag} / \mathrm{AgCl}$. However, at a potential of $-1.00 \mathrm{~V}$ vs. $\mathrm{Ag} / \mathrm{AgCl}$, the atomic fractions of the three components are mostly equal to each other with the composition ratio about 1:1:1.

Fig. 3a compares the hysteresis loops of the FeCoNi films prepared at potentials of $-1.00 \mathrm{~V}$, $-1.30 \mathrm{~V}$ and $-1.75 \mathrm{~V}$. Evaluation of magnetic properties of $\mathrm{FeCoNi}$ alloy films was carried out in two different directions. The two directions were marked as IP (in-plane) and OP (out-plane) which refer to parallel and perpendicular to the direction of the applied magnetic field, respectively. Hysteresis loops shown in Fig. 3a are typical of that of soft magnetic films. The saturation magnetization state is achieved mostly at a relatively small external magnetic field. This result is confirmed by FeCoNi films prepared at the electrodeposition potentials of $-1.00 \mathrm{~V},-1.30 \mathrm{~V}$ and $-1.75 \mathrm{~V}$ vs. $\mathrm{Ag} / \mathrm{AgCl}$. For the latter, a slightly higher magnetic field was required to achieve the saturation state due to the anisotropy characteristic of that sample. Although the sample shows anisotropy
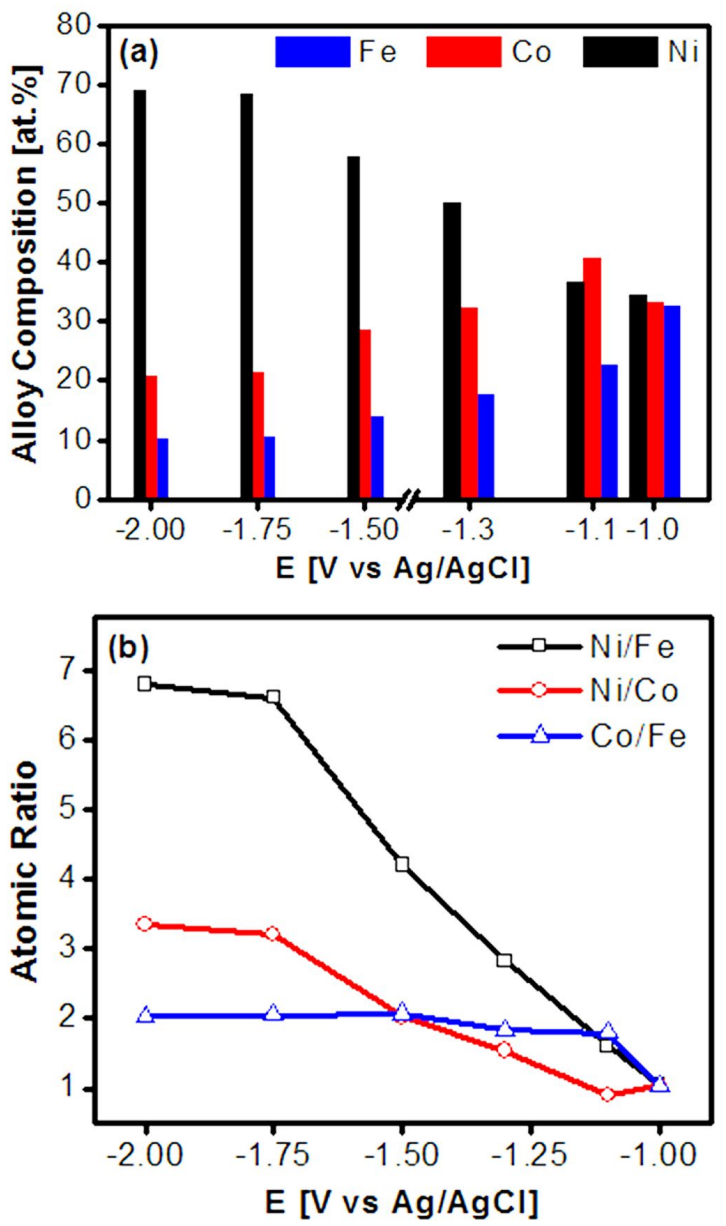

Fig. 2. Atomic composition of $\mathrm{Ni}, \mathrm{Co}$ and $\mathrm{Fe}$ (a) and atomic ratio $\mathrm{Ni} / \mathrm{Fe}, \mathrm{Ni} / \mathrm{Co}, \mathrm{Co} / \mathrm{Fe}$ values (b) in FeCoNi films prepared at different electrodeposition potentials.

characteristics, the saturation magnetization value of each sample is the same for both directions (IP and OP). Generally, the magnetic anisotropy of the sample can be associated with the crystalline anisotropy and shape anisotropy. The crystalline anisotropy in the sample would take effect when crystallites of magnetic phase are oriented to a preferred direction. For this case, it still cannot be confirmed if the preferred orientation of the crystallites can induce the magnetic anisotropy of the FeCoNi films deposited at different co-deposition potentials. However, since the length $L$ to thickness $\mathrm{T}$ ratio of the film (L:T) is in the range of 16000 to 30000 , then the magnetic anisotropy observed in the sample prepared at an electrodeposition 

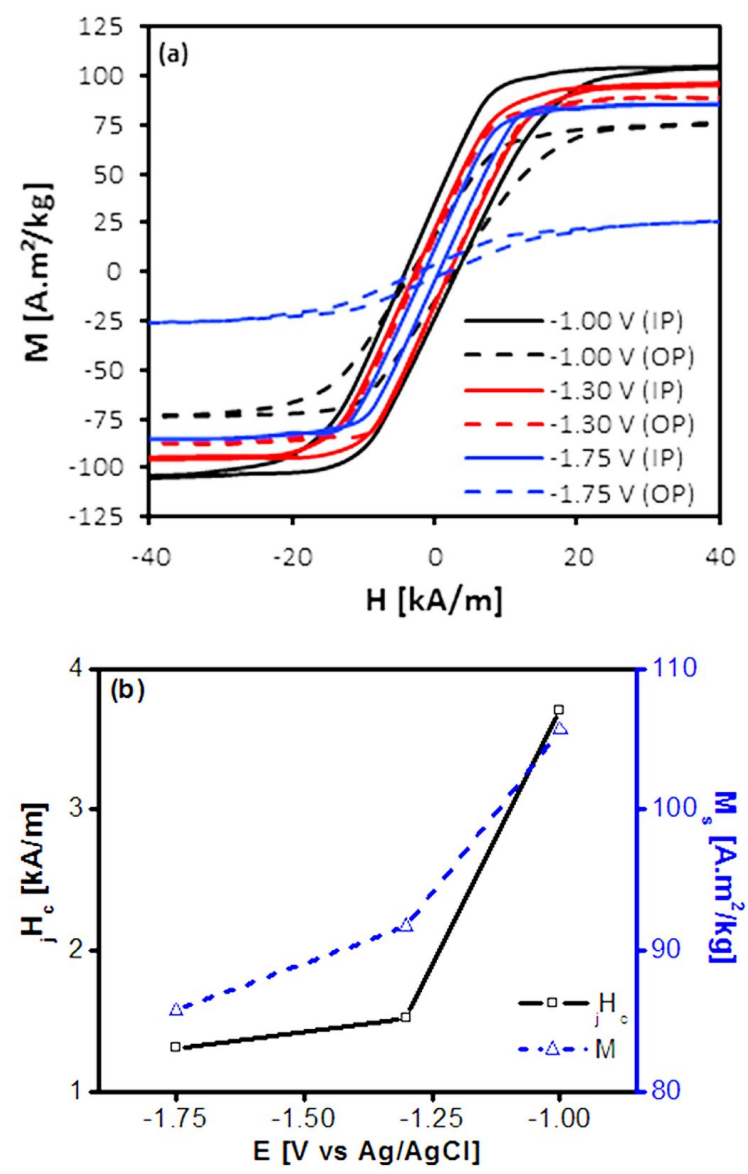

Fig. 3. Hysteresis loops of FeCoNi films (a) prepared at various electrodeposition potentials and (b) the corresponding intrinsic coercivity $\left({ }_{\mathrm{j}} \mathrm{H}_{\mathrm{c}}\right)$ and saturation magnetization $\left(\mathrm{M}_{\mathrm{s}}\right)$ values obtained from IP loops.

potential of $-1.75 \mathrm{~V}$ vs. $\mathrm{Ag} / \mathrm{AgCl}$ is more likely due to a shape anisotropy of the sample.

Both saturation magnetization and coercivity values of the samples increased as the electrodeposition potential became less negative. The increase in saturation magnetization value is due to the higher content of $\mathrm{Fe}$ and $\mathrm{Co}$ atoms, and lower content of $\mathrm{Ni}$ in the FeCoNi alloy. This condition was followed by an increase in the corresponding coercivity.

In the previous discussion, we have shown that the applied potential during electrodeposition of FeCoNi films caused a change in the composition. The variation in the composition of the alloy film
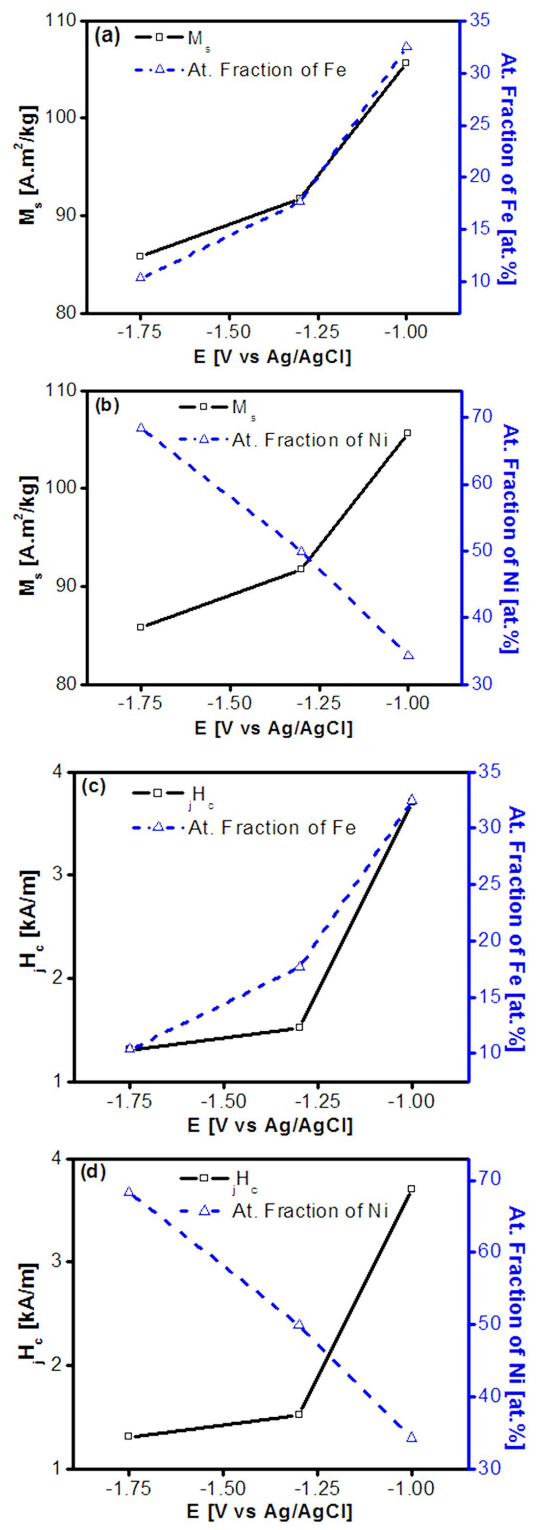

Fig. 4. Composition dependent intrinsic coercivity $\left(\mathrm{j}_{\mathrm{c}}\right)$ and saturation magnetization $\left(\mathrm{M}_{\mathrm{s}}\right)$ values of FeCoNi films measured in IP directions

resulted in a modification in the magnetic properties of FeCoNi films. The plots of $\mathrm{M}_{\mathrm{s}}$ and ${ }_{\mathrm{j}} \mathrm{H}_{\mathrm{c}}$ values of FeCoNi films of various compositions are shown in Fig. 4. It shows an increase in both $\mathbf{M}_{\mathrm{s}}$ and ${ }_{j} \mathrm{H}_{\mathrm{c}}$ values with an increase in Fe content in the FeCoNi film (Fig. 4a and $4 \mathrm{c}$ ). The $\mathrm{M}_{\mathrm{s}}$ and ${ }_{\mathrm{j}} \mathrm{H}_{\mathrm{c}}$ values get increased with a decrease in Ni content (Fig. $4 \mathrm{~b}$ and $4 \mathrm{~d}$ ). The reason for these results is that the net magnetic moment of Fe atom $(2.22 \mu \mathrm{B})$ [25] 
is the highest among the three transition metals followed by $\mathrm{Co}(1.72 \mu \mathrm{B})$ and $\mathrm{Ni}(0.60 \mu \mathrm{B})$ [25]. It is known that magnetization and coercivity are properties which depend on microstructure and chemical composition of materials [5, 10, 26]. However, since there is no meaningful change in the crystallite size of the electrodeposited FeCoNi alloys, the changes in their magnetic characteristics could be solely attributed to the chemical composition of the alloy. In this case, once again the increase in $\mathrm{Fe}$ and Co content resulted in the increasing saturation magnetization. However, the change in coercivity is more likely due to the change in the magnetocrystalline constant of the FeCoNi.

\section{Conclusion}

This study demonstrates the influence of the applied potential on magnetic properties of electrodeposited FeCoNi films. The magnetic properties were found to be solely dependent on the atomic fraction of $\mathrm{Fe}, \mathrm{Co}$ and $\mathrm{Ni}$ atoms, which was successfully controlled through the adjustment of the electrodeposition potential because there was no significant change found in the crystallite size. The FeCoNi films possess excellent soft magnetic properties with the highest $\mathrm{M}_{\mathrm{s}}$ value of $105 \mathrm{~A} \cdot \mathrm{m}^{2} / \mathrm{kg}$ and ${ }_{\mathrm{j}} \mathrm{H}_{\mathrm{c}}$ value of $3.7 \mathrm{kA} / \mathrm{m}$ obtained at the electrodeposition potential of $-1.00 \mathrm{~V}$ vs. $\mathrm{Ag} / \mathrm{AgCl}$ with the $\mathrm{Fe}, \mathrm{Co}$ and Ni composition close to $1: 1: 1$.

\section{Acknowledgements}

This work was supported by the Universitas Negeri Jakarta and the Directorate General of the Higher Education (RISTEKDIKTI) Republic of Indonesia through the Research Grant of Penelitian Terapan with the Contracts No. 60/SP2H/DRPM/LPPM-UNJ/II/2018 and No. 27/SP2H/DRPM/LPPM-UNJ/III/2019.

\section{References}

[1] Osaka T., Takai M., Hayashi K., Ohashi K., Nature, 392 (1998), 796.

[2] Luciu I., Duday D., Choquet P., Perigo E.A., Michels A., Wirtz T., Appl. Surf. Sci., 389 (2016), 578.

[3] Pikula T., Oleszak D., MareK P., J. Magn. Magn. Mater., 320 (2008), 413.
[4] Fu P., Chen G., Xu Y., Cai P., WAng X.H., Mater. Sci.-Poland, 30 (2012), 259.

[5] RaAnaei H., Eskandari H., MohammadHosseini V., J. Magn. Magn. Mater, 398 (2016), 190.

[6] Baghbaderani H.A., Shara S., Chermahini M.D., Powder Technol., 230 (2012), 241.

[7] Shakya P., Cox B., Davis D., J. Magn. Magn. Mater., 324 (2012), 453.

[8] Duan Y., Zhang Y., Wang T., Gu S., Xin L., Xingzun L.V., Mater. Sci. Eng. B-Adv., 185 (2014), 86.

[9] Ali G.A.M., Yusoff M.M., NG Y.H., LiM H.N., ChOng K.F., Curr. Appl. Phys., 15 (2015), 1143.

[10] Daud A.R., Budi S., Radiman S., Sains Malaysiana, 40 (2011), 1019.

[11] Hanafi I., Daud A.R., Radiman S., Gani M.H.A., Budi S., J. Phys. Conf. Ser., 431 (2013), 1.

[12] Hanafi I., Daud A.R., Radiman S., Port. Electrochim. Acta, 35 (2017), 1.

[13] Talik E., GuZiK A., Zajdel P., Lipińska L., BARAN M., SzUBKA M., Mater. Res. Bull., 83 (2016), 56.

[14] Akbulut S., Akbulut A., Özdemir M., Yildiz F., J. Magn. Magn. Mater., 390 (2015), 137.

[15] Budi S., Hafizah M.E., Manaf A., AIP, 1746 (2016), 020012-1.

[16] Budi S., Kurniawan B., MotT D.M., Maenosono S., Umar A.A., ManaF A., Thin Solid Films, 642 (2017), 51.

[17] Xiao L., Chen Z., Feng C., LiU L., Bai Z.-Q., WANG Y., QIAN L., Zhang Y., Li Q., JiAnG K., FAN S., Nano Lett., 8 (2008), 4539.

[18] LeE H., WANG L., BAIN J.A., LAUGhlin D.E., IEEE T. Magn., 41 (2005), 654.

[19] Budi S., Daud A.R., Radiman S., Umar A.A., Appl. Surf. Sci., 257 (2010), 1027.

[20] Matlosz M., J. Electrochem. Soc., 140 (1993), 2272.

[21] Grazulis S., Chateigner D., Downs R.T., Yokochi A.F.T., Quirós M., LutTerotTi L., Manakova E., ButKus J., Moeck P., Le Bail A., J. Appl. Crystallogr., 42 (2009), 726.

[22] Veith M., Bubel C., Zimmer M., Dalt. Trans., 40 (2011), 6028.

[23] Dolati A., Sababi M., Nouri E., Ghorbani M., Mater. Chem. Phys., 102 (2007), 118.

[24] YANG Y., Int. J. Electrochem. Sci., 10 (2015), 5164.

[25] Cullity B.D., Graham C.D., Introduction to Magnetic Materials, John Wiley \& Sons, New Jersey, 2008.

[26] Veligatla M., Katakam S., Das S., Dahotre N., Gopalan R., Prabhu D., BAbU D.A., ChOIYim H., MukherJeE S., Metall. Mater. Trans., A 46 (2015), 1019.

Received 2018-04-07 Accepted 2018-11-12 